\title{
Short Term in vitro Culture of Cryptocaryon irritans, a Protozoan Parasite of Marine Fishes
}

\author{
Apolinario V. Yambot ${ }^{1,3}$ and Yen-Ling Song ${ }^{1,2 *}$ \\ ${ }^{1}$ Institute of Zoology, National Taiwan University, Taipei 106, Taiwan, ROC \\ ${ }^{2}$ Department of Life Science, National Taiwan University, \\ Taipei 106, Taiwan, ROC \\ ${ }^{3}$ Present address: College of Fisheries-Freshwater Aquaculture Center, \\ Central Luzon State University, Philippines
}

(Received March 19, 2004)

\begin{abstract}
Attempts were made to cultivate Cryptocaryon irritans in vitro at $23-25^{\circ} \mathrm{C}$. Attachment of theronts and subsequent enlargement into trophonts were achieved in two experiments using strips of trypticase soy agar (TSA, supplemented with $3 \% \mathrm{NaCl}$ ) as an attachment substrate in filtered seawater. In the third experiment, transformation of theronts into trophonts was achieved in an enriched liquid medium composed of $50 \%$ filtered seawater, $30 \%$ Leibovitz L-15 and $20 \%$ fetal calf serum without attachment onto the TSA. Sizes (mean \pm SD) of the trophonts, 114.6 $\pm 57.9 \mu \mathrm{m}$ to $295.9 \pm 130 \mu \mathrm{m}$, were from a recorded size range (50 to $700 \mu \mathrm{m})$ of the parasite in vivo. Although only limited numbers of theronts $(0.28-1.71 \%)$ transformed into trophonts, these results showed that the in vitro culture of $C$. irritans is potentially feasible as evidenced by the enlargement of the trophonts within the in vivo size range using either a solid medium as an attachment substrate or a liquid medium without attachment. There is a need, however, to determine essential factors that influence the transformation of the trophonts into viable tomonts capable of producing theronts.
\end{abstract}

Key words: Cryptocaryon irritans, in vitro culture, theront, trophont, culture media

The white spot disease in marine fishes caused by the ciliated protozoan parasite, Cryptocaryon irritans, is posing a problem to marine aquaculture. The parasite is considered one of the most devastating parasites of cultured marine fishes. Ornamental, wild and cultured fish species in marine cages and pens are included in the list of hosts of $C$. irritans. The parasite is widely distributed in various marine waters worldwide (Colorni and Burgess, 1997). Diversified isolates of C. irritans, including a low salinity variant infecting pond-reared sea bream, were characterized recently by Yambot et al. (2003).

Earlier works demonstrated that freshwater fish acquire immunity against Ichthyophthirius multifiliis, a freshwater counterpart of $C$. irritans (Clark et al., 1987, 1988; Burkart et al., 1990). Similarly, resistance against $C$. irritans has been observed in fish surviving from the infection of the parasite (Burgess and

\footnotetext{
* Corresponding author

E-mail: song@ccms.ntu.edu.tw
}

Matthews, 1995; Dickerson and Clark, 1996; Yoshinaga and Nakazoe, 1997). Manifestation of acquired protective immunity in the different fish species against $C$. irritans suggests a potential role of vaccine as a prophylactic measure.

Under laboratory conditions, immunization of fish against the parasite looked promising (Burgess and Matthews, 1995; Yoshinaga and Nakazoe, 1997; Bryant et al., 1999). However, difficulty in obtaining a sufficient amount of parasite organisms for large-scale production of the vaccine is a major problem. Continuous propagation of the parasite in vivo requires considerable space, effort and resources. Moreover, maintaining a constant supply of healthy host fish to produce large amounts of parasites for vaccine development is costly and impractical.

In vitro cultures of other protozoan parasites of fishes had been performed by various researchers (Uzmann and Hayduk, 1963; Noga, 1987; Noga and Bower, 1987; Woo and Li, 1990; Wang and Belosevic, 1994). The in vitro techniques reduce space and other 
resources and eliminate the use and maintenance of living host fishes. The in vitro culture aiming for a sustained growth of $I$. multifiliis has been previously attempted (Noe and Dickerson, 1995; Ekless and Matthews, 1993; Nielsen and Buchmann, 2000). The in vitro propagation appears a promising alternative for producing the parasite in sufficient quantity to immunize the fish against white spot disease.

The present study reports the results of the first phase of experiments on the screening of different media for the in vitro culture of the protozoan parasite, $C$. irritans. Some features of the trophont produced in vitro were also discussed.

\section{Materials and Methods}

\section{Maintenance of the parasite}

Samples of $C$. irritans-infected grouper Epinephelus coioides were sourced out from a live fish markets in
Taipei, Taiwan. Infected samples were chosen based on the appearance of white spots on the body of the fish. Healthy naïve grouper fingerlings (each $4-6 \mathrm{~cm}$ in length) were procured from a hatchery in southern Taiwan. The fingerlings which were reared in tanks and fed with fresh small shrimp at least one week prior to infection were used for the in vivo propagation of the parasite.

After their exit from the original host, 10 to 20 tomonts of $C$. irritans were seeded into a $1 \mathrm{~L}$ beaker with one fingerling for infection by the excysting theronts. Salinity of the seawater was maintained at $35 \mathrm{ppt}$. Moderate aeration was given in each beaker. Fish feeding was discontinued while infection was in progress. When necessary, partial water change and collection of fecal matters and other debris by siphoning were done with great care in each vessel. When most of the trophonts have exited from the experimentally infected fish body and transformed to tomonts, the fish

Table 1. Description of the different media used in the three experiments and summary of results

\begin{tabular}{|c|c|c|c|c|c|c|}
\hline Treatments & $\begin{array}{l}\text { Composition } \\
\text { of media }\end{array}$ & $\begin{array}{c}\text { Number of } \\
\text { tomonts seeded }\end{array}$ & $\begin{array}{c}\text { Transformation } \\
\text { into trophont }\end{array}$ & $\begin{array}{l}\text { Substrate for } \\
\text { trophont growth }\end{array}$ & $\begin{array}{c}\text { Trophont survival } \\
\text { after transformation, } \\
\text { days }\end{array}$ & $\begin{array}{l}\text { Trophont diameter } \\
\text { (mean } \pm \text { SD), } \mu \mathrm{m}\end{array}$ \\
\hline \multicolumn{2}{|c|}{ Experiment 1} & 10 (in $50 \mathrm{~mL}$ flask) & & & & \\
\hline T1 & seawater & & no & NTG & - & - \\
\hline $\mathrm{T} 2$ & $\begin{array}{l}\text { seawater, } \\
\text { TSA }\end{array}$ & & yes & agar & $10-13$ & $117.8 \pm 31.5(n=50)^{b}$ \\
\hline T3 & $\begin{array}{l}\text { seawater }(75 \%) \\
\text { L15 }(22.5 \%) \\
\text { FCS }(2.5 \%) \\
\text { TSA }\end{array}$ & & yes & agar & $10-13$ & \\
\hline \multicolumn{2}{|c|}{ Experiment 2} & 3/well (12-well plates) & & & & \\
\hline T1 & $\begin{array}{l}\text { seawater }(75 \%) \\
\text { L15 }(22.5 \%) \\
\text { FCS }(2.5 \%) \\
\text { TSA }\end{array}$ & & yes & agar & 8 & $114.6 \pm 57.9(n=20)$ \\
\hline $\begin{array}{l}\mathrm{s} \\
\mathrm{L} \\
\mathrm{ti} \\
\mathrm{T}\end{array}$ & $\begin{array}{l}\text { seawater }(75 \%) \\
\text { L15 }(22.5 \%) \\
\text { tilapia serum }(2.5 \%) \\
\text { TSA }\end{array}$ & & yes & agar & 4 & $140.2 \pm 16.0(n=5)$ \\
\hline $\begin{array}{ll}\text { T3 } & J \\
& \mathrm{~L} \\
& \mathrm{~F}\end{array}$ & $\begin{array}{l}\text { JF1 (epithelial cells) } \\
\text { L15 (95\%) } \\
\text { FCS }(5 \%)\end{array}$ & & no & NTG & - & - \\
\hline \multicolumn{2}{|c|}{ Experiment 3} & 3/well (12-well plates) & & & & \\
\hline $\begin{array}{ll}\mathrm{T} 1 \mathrm{~S} \\
\mathrm{~L} \\
\mathrm{~F} \\
\mathrm{~T}\end{array}$ & $\begin{array}{l}\text { seawater }(50 \%) \\
\text { L15 }(30 \%) \\
\text { FCS }(20 \%) \\
\text { TSA }\end{array}$ & & yes & liquid & 8 & $292.9 \pm 130.0(n=30)$ \\
\hline T2 & $\begin{array}{l}\text { seawater }(50 \%) \\
\text { L15 }(30 \%) \\
\text { FCS }(20 \%)\end{array}$ & & yes & liquid & 8 & $206.4 \pm 100.2(n=10)$ \\
\hline $\begin{array}{l}S \\
L \\
g \\
T\end{array}$ & $\begin{array}{l}\text { seawater }(50 \%) \\
\text { L15 }(30 \%) \\
\text { grouper serum }(20 \%) \\
\text { TSA }\end{array}$ & & no & NTG & - & - \\
\hline T4 & $\begin{array}{l}\text { seawater }(50 \%) \\
\text { L15 }(30 \%) \\
\text { grouper serum }(20 \%)\end{array}$ & & no & NTG & - & - \\
\hline
\end{tabular}

${ }^{\text {a }}$ Includes those media with trophonts; NTG - no trophont growth

${ }^{\mathrm{b}}$ Sizes of trophonts $( \pm \mathrm{SD})$ were pooled from T2 and T3 
hosts were transferred to a new confinement. The adhering tomonts were detached from the bottom of the beakers using a fine paintbrush. The tomonts were collected by siphoning, cleaned of debris, and seeded into a new beaker to infect another naïve host fish.

\section{In vitro culture of parasite}

Three in vitro culture experiments were carried out. The composition of the different media in each treatment is presented in Table 1. Seawater used was filter-sterilized $(0.22 \mu \mathrm{m})$ and each treatment was replicated three times. Leibovitz L15 medium (supplemented with $3 \% \mathrm{NaCl}$ ) and trypticase soya agar (TSA, supplemented with $3 \% \mathrm{NaCl}$ ) were prepared separately and sterilized as recommended by manufacturers. Fetal calf serum (FCS) was heat-inactivated at $56^{\circ} \mathrm{C}$ for $20 \mathrm{~min}$ and immediately stored at $-80^{\circ} \mathrm{C}$ prior to use. Incubation temperature for the in vitro growth of the parasite in culture flasks and plates was maintained at 23 to $25^{\circ} \mathrm{C}$ in a cell culture incubator. Monitoring of the parasite growth in culture flasks and plates was done two times daily using an inverted microscope. Surviving theronts and trophonts were assessed as alive based on ciliary beating and intact bodies. Photographic documentation of the in vitro raised trophonts at 5-day post-seeding was done to record their sizes and other features.

\section{Experiment 1}

Late stage tomonts of $C$. irritans with moving theronts inside the cysts (ready to excyst) were collected from the in vivo maintenance of the parasite. The tomonts were further cleaned of debris and washed three times with seawater. The tomonts were then washed and soaked three times in filtered seawater with

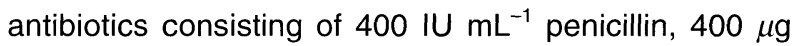
$\mathrm{mL}^{-1}$ streptomycin and $1 \mu \mathrm{g} \mathrm{mL}^{-1}$ fungizone for $5 \mathrm{~min}$ each wash, with a quick dip into seawater without antibiotics between the washes.

Ten tomonts were seeded into each of $50-\mathrm{mL}$ tissue culture flasks. Liquid medium was maintained at $20 \mathrm{~mL}$ in each flask. The treatments were T1 (seawater as a control), T2 (seawater, TSA strips), and T3 (75\% seawater, $22.5 \%$ L15, 2.5\% FCS, TSA strips). The TSA (3\% $\mathrm{NaCl}$ ) was prepared and cut aseptically into strips using a sterile surgical blade. The size of the TSA strips was approximately $0.15 \mathrm{~cm} \times 0.25 \mathrm{~cm} \times 0.5 \mathrm{~cm}$; five TSA strips were introduced into each flask in T2 and T3. Antibiotics containing $100 \mathrm{IU} \mathrm{mL} \mathrm{m}^{-1}$ penicillin, $100 \mu \mathrm{g} \mathrm{mL}^{-1}$ streptomycin and $0.25 \mu \mathrm{g} \mathrm{mL}^{-1}$ fungizone was added into each flask.

\section{Experiment 2}

The second experiment was conducted using three treatments: T1 (75\% seawater, $22.5 \%$ L15, 2.5\% FCS), T2 (75\% seawater, $22.5 \%$ L 15, $2.5 \%$ tilapia serum) and
T3 (JF1 epithelial cells from javelin grunter Pomadasys kaakan, 95\% L-15, 5\% FCS). Bleeding was carried out in tilapia hybrids, Oreochromis sp. (200 g each), using a 5-mL syringe punctured through the dorsal aorta of the caudal peduncle. The blood was placed separately into Eppendorf tubes and allowed to clot overnight at $4^{\circ} \mathrm{C}$. The fish serum was then separated by centrifugation at $1000 \times g$ for $10 \mathrm{~min}$, heat-inactivated at $45^{\circ} \mathrm{C}$ for 20 min according to Yano (1992) and immediately stored at $-80^{\circ} \mathrm{C}$ prior to use. The epithelial cells (JF1 cells, gift from Dr. Shau-Chi Chi) were cultured as a monolayer in cell culture flasks using L-15 medium supplemented with $5 \%$ FCS.

The culture of $C$. irritans was performed in 12-well culture plates, each well containing $2 \mathrm{~mL}$ liquid media. TSA strips were added into T1 and T2 as solid substrate for the attachment of the parasites. The monolayer of the JF1 cells was added in T3 as another attachment substrate. The tomonts seeded into the wells were prepared according to the procedure described above. Each well was seeded with three tomonts. Since bacterial contamination was observed in the culture flasks in Experiment 1, ciproxin was used as antibiotics and introduced at a dose of $100 \mu \mathrm{g} \mathrm{mL}^{-1}$ into each well.

\section{Experiment 3}

The culture of the parasite was carried out in 12-well tissue culture plates using four treatments: T1 (50\% seawater, 30\% L15, 20\% FCS, TSA strips), T2 (50\% seawater, 30\% L15, 20\% FCS), T3 (50\% seawater, 30\% L15, $20 \%$ grouper serum, TSA strips) and T4 (50\% seawater, $30 \%$ L15, 20\% grouper serum). The serum concentration was increased to $20 \%$ to provide more essential nutrients following that of the primary culture of animal cells (Chi et al., 1999; Freshney, 2000). Collection of blood from the grouper (300 $\mathrm{g}$ body weight) and serum preparation were performed as described above.

Each well contained $2 \mathrm{~mL}$ liquid media. The tomonts were cleaned as described above. Three tomonts were introduced into each well. To compare the sizes of in vitro raised trophonts and in vivo trophonts, grouper fingerlings were simultaneously infected with the parasite by exposing the fish to theronts. Since fungal contamination of the media was sometimes encountered during the previous trials while culture was in progress, a fungicide Fungizone (Amphotericin B $250 \mu \mathrm{g} \mathrm{mL}^{-1}$, Gibco USA) was added into each well to a final concentration of $0.25 \mu \mathrm{g} \mathrm{mL}^{-1}$. Ciproxin concentration was maintained at $100 \mu \mathrm{g} \mathrm{mL} \mathrm{m}^{-1}$ in each well.

\section{$D A P I$ staining of trophonts}

Nuclear staining of the in vivo and in vitro raised trophonts was done using 4',6-diamidino-2-phenylindole (DAPI). Naturally infected fish were fixed with $8 \%$ neutral buffered formalin at 5-day post-seeding of mature 
tomonts. The in vitro raised trophonts were collected from culture plates in Experiment 3 at 5-day postseeding. The in vivo and in vitro raised trophonts were placed on depression slides, separately flooded with methanol and air dried. The trophont samples were then immersed into DAPI (in $0.1 \%$ Triton X-100 in PBS) for $5 \mathrm{~min}$, overlaid with Fluoromount $\mathrm{G}$ (Electron Microscopy Science, USA), and incubated in the dark for 24 h. Observation of the trophonts was done using the Leica DM IRE2 microscopy (Leica Microsystems, Germany).

\section{Statistical analysis}

The sizes in diameter of in vitro raised trophonts in Experiment 2 were analyzed using Student's T test. The in vitro raised trophont sizes were compared with the in vivo trophont sizes in Experiment 3 using Analysis of Variance (ANOVA).

\section{Results}

\section{Transformation of theronts to trophonts}

Results of the three experiments are summarized in Table 1. Theronts of $C$. irritans were observed to have transformed into trophonts in all of the three in vitro culture trials using either solid or liquid media. The theronts that attached to the TSA in Experiments 1 and 2 and subsequently enlarged were considered as trophonts (Fig. 1). While in Experiment 3, the theronts that transformed in the liquid media and increased in sizes greater than $90 \mu \mathrm{m}$ were identified as trophonts (Figs. 2 \& 3). No in vitro raised trophont was observed to have transformed into tomonts.

In Experiment 1, the attachment and growth of trophonts appearing as white spots were noted on the TSA solid substrate immersed in seawater alone (T2)

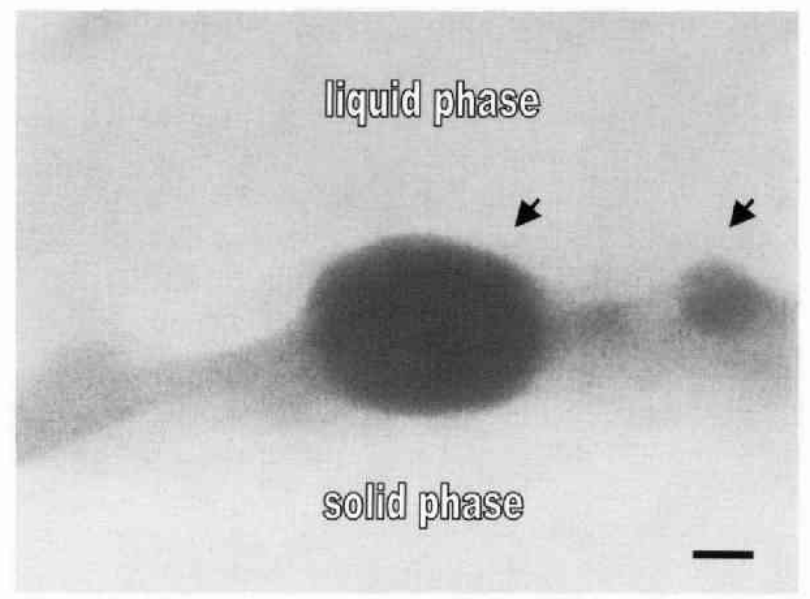

Fig. 1. Trophonts (arrow) in Experiment 2 (fish serum-supplemented liquid medium) showing half of the cell burrowed into TSA (scale bar $=50 \mu \mathrm{m}$ ).

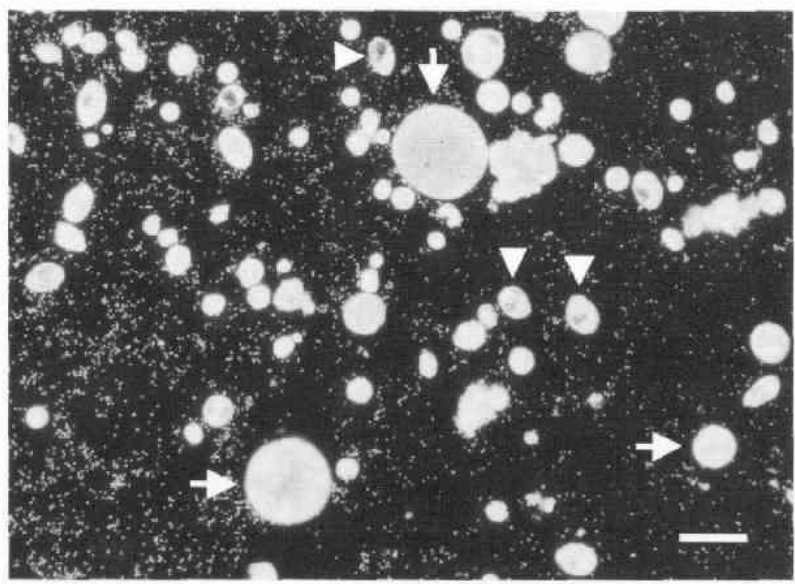

Fig. 2. Different sizes of in vitro trophonts (long arrows) and vacuolated theronts (short arrows) in the liquid medium in Experiment 3 (scale bar $=200 \mu \mathrm{m}$ ).
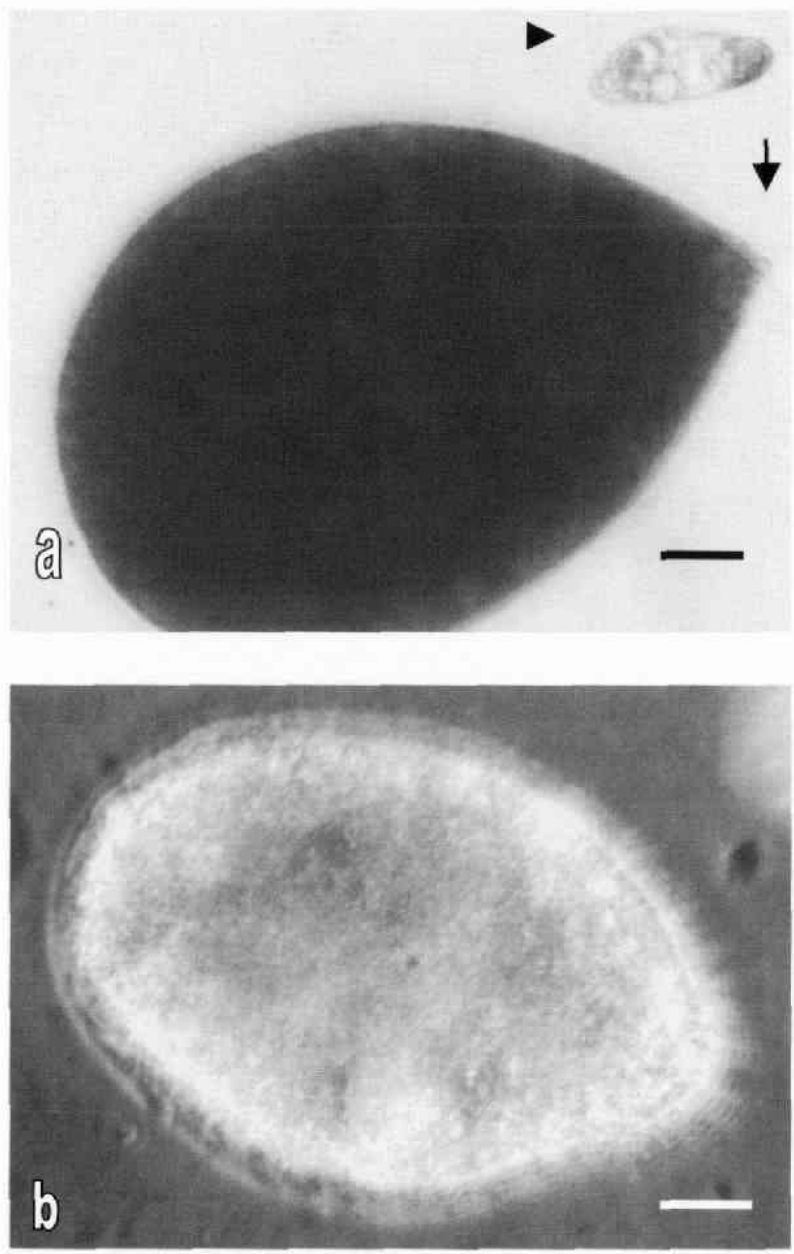

Fig. 3. Pear-shaped in vitro trophonts in the liquid medium in Experiment 3. (a) A trophont showing cilia and cytostome (long arrow) at tapering end and a vacuolated theront (short arrow) (scale bar $=40 \mu \mathrm{m}$ ). (b) A trophont showing clearer ciliary structures (scale bar = $20 \mu \mathrm{m})$. (Phase-contrast) 

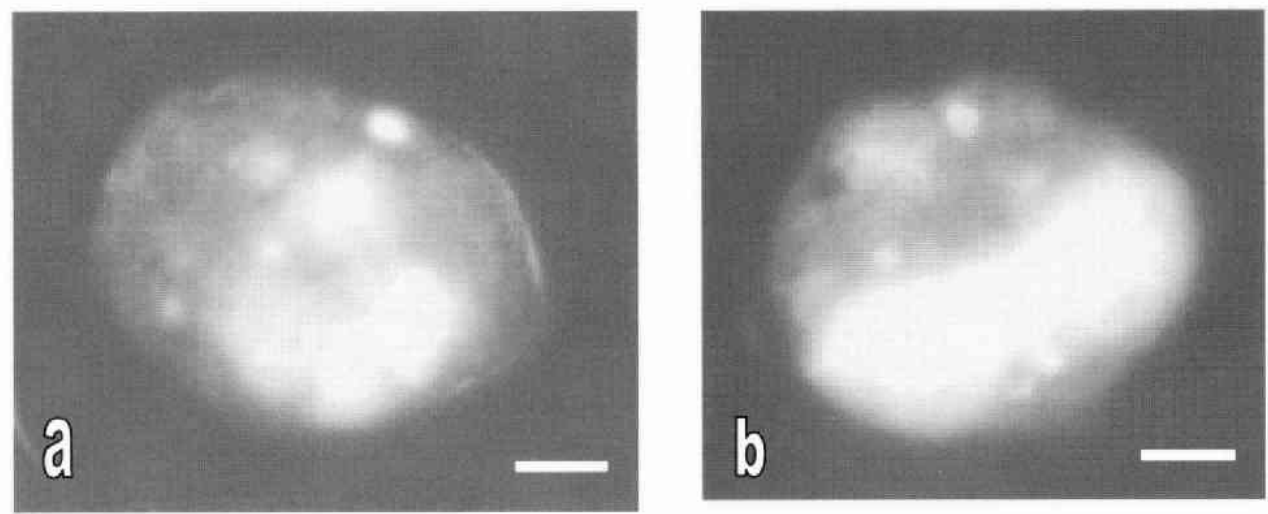

Fig. 4. DAPI staining of in vitro raised trophonts from Experiment 3 showed (a) four-lobed macronucleus and (b) elongated macronucleus (scale bar $=20 \mu \mathrm{m}$ ).

and in the liquid medium consisting of seawater, L15 and FCS (T3). The trophonts (ca 26 trophonts in $1 \mathrm{~mm}^{2}$ on sides with growth; none on the bottom side touching the flask) survived for 10 to 13 days and exhibited intact bodies after which lysis of the cells was noted. Mean size of the trophonts was $117.8 \pm 31.5 \mu$ m (mean \pm SD; $n=50$ ) at 5-day post-seeding of tomonts.

In Experiment 2, theronts transformed into trophonts on the TSA substrate (Fig. 1) with the basal medium (seawater and Leibovitz L15) supplemented with FCS (T1) or tilapia serum (T2). The trophonts attached and enlarged on the medium and survived for eight days in T1 and four days in T2. Percent of theronts that transformed to trophonts burrowed in TSA (calculated as the number of in vitro raised trophonts divided by the total number of theronts and trophonts $\times 100 \%$ ) were estimated at $0.28 \%(\mathrm{~T} 2)$ and $1.14 \%(\mathrm{~T} 1)$ at 5 -day postseeding. A number of in vitro raised trophonts, however, were noted to be dead before the estimate.

Theronts were also observed to probe the monolayer culture of the JF1 cells (T3) but dislodged the cells from attachment. In addition, the cells surrounding the point of theront penetration were lysed a couple of hours after invasion. Ciliary beating was observed on the live theronts while lysis of the body was noted on the dead parasites.

Fewer theronts transformed into trophonts and survived for a shorter period in cultures supplemented with tilapia serum compared to those with FCS. The trophonts, however, were larger in the presence of tilapia serum (140.2 $\pm 16.0 \mu \mathrm{m} ; \mathrm{n}=5$ ) compared to FCS (114.6 $\pm 57.9 \mu \mathrm{m} ; \mathrm{n}=20$ ) but no significant difference was detected between the two treatments (Student's T test, $p>0.01)$.

In Experiment 3,1.71\% of the theronts transformed into trophonts without attaching to the TSA substrate at 5-day post-seeding (Fig. 2) in a medium consisting of seawater, L15 and FCS (T1). The transformation was also recorded in a medium without the TSA substrate (T2). The sizes of the in vitro raised trophonts in T1
$(295.9 \pm 130 \mu \mathrm{m} ; \mathrm{n}=30)$ were not significantly different from those in T2 (206.4 $\pm 100.2 \mu \mathrm{m} ; \mathrm{n}=10)$ and those of the in vivo trophonts $(332.7 \pm 52 \mu \mathrm{m} ; \mathrm{n}=20)$ of the same parasite strain (Student's $T$ test, $p>0.01$ ). However, there was a significant difference between the sizes of the in vitro raised trophonts in T2 and the in vivo trophonts $(p<0.01)$. No transformation of theronts was noted in the medium supplemented with grouper serum (T3 and T4). The theronts survived for several hours in the medium with the grouper serum while the trophonts survived for eight days in FCS-supplemented medium (T1 and T2).

\section{Features of the trophonts}

Short ciliatures were conspicuously present in most of the in vitro raised trophonts in the liquid media but were difficult to detect, using microscopy, in the trophonts attached to the TSA (Fig. 1). The trophonts in the liquid media were either spherical like a ball (Fig. 2) or pear-shaped which tapers on one end (Figs. 3a, b) with fragile and sticky body surfaces, particularly for large trophonts. Spherical trophonts were observed to retain their shape as they enlarged. Pear-shaped trophonts likewise retained their shape as they grew. A cytostome was easily recognized in the pear-shaped trophonts (Fig. 3a) but could hardly be detected in spherical trophonts. The cytostome appeared in distended form in these spherical trophonts. DAPI-stained small in vitro raised trophonts showed a macronucleus consisting of either four bead-like segments (Fig. 4a) or elongated form (Fig. 4b). DAPI-stained large in vivo trophonts showed much bigger stained mass filling the cell alveoli.

\section{Discussion}

In the present study, attachment of the trophonts of Cryptocaryon irritans to a solid medium (TSA) and transformation of the theronts to trophonts in a liquid medium were both achieved. 
Published data on sizes of trophonts burrowed in fish host ranged from as low as $50 \mu \mathrm{m}$ to as high as 700 $\mu \mathrm{m}$ (Colorni and Burgess, 1997; Jee et al., 2000). In the present study, the sizes of the pear-shaped theronts were from 34 to $45 \mu \mathrm{m}$ in width and from 59 to $72 \mu \mathrm{m}$ in length while the sizes of the in vitro trophonts were within the recorded size range of the parasite in vivo. The sizes of the in vitro raised trophonts in the liquid medium (T1, Experiment 3) were also comparable to the in vivo trophonts of the same parasite strain. The sizes of the trophonts particularly in the first two experiments, however, were at a lower bracket of the in vivo size range.

The ciliary structure of the in vitro raised trophonts in the present study, particularly those in the liquid media, corresponded to the description given by Colorni and Diamant (1993) that in vivo trophonts have short and fine ciliature. Some of the in vitro raised trophonts exhibited rotating motion which was also noted by Colorni and Burgess (1997) on trophonts within the host epithelium. Similar movement, however, was not observed in the TSA-attached trophonts even as they enlarged.

The attachment and subsequent enlargement of the parasite as trophonts on the TSA solid substrate are likely to mimic the invasion and development of the parasite on the fish host. It is puzzling though that the attachment and transformation of theronts on the solid media were not observed in some replicates of T2 and T3 in Experiment 1.

An in vitro cultivation of Ichthyophthirius multifilis, the freshwater counterpart of $C$. irritans, was done by Nielsen and Buchmann (2000) who observed the transformation of theronts to trophonts. The authors reported that the presence of fish epithelial cells improved the in vitro cultivation in terms of days of survival. In the present study, the theronts were evidently attracted to the epithelial cells as shown by their active probing of the monolayer culture in T3 in Experiment 2. The theronts transformed to spherical shape a few hours after penetration but subsequent growth was not observed since the parasites and the dislodged monolayer culture did not survive long enough in contrast to Nielsen and Buchmann (2000).

In the medium supplemented with grouper serum in Experiment 3, lysis of the theronts was observed after several hours. This indicates that using the same amount of serum $(20 \%)$, the grouper serum did not serve as a substitute for the FCS in the culture media. The heat-inactivated serum, although taken from a naïve grouper, possibly contained factors detrimental to the parasite. In Experiment 2, theronts transformed to trophonts that survived for four days in the medium with much lower amount of fish serum (2.5\%), although tilapia was used as a source.

It is probable that an increase in FCS supplementation from 2.5\% in Experiment 2 to $20 \%$ in Experiment 3 has largely contributed to the transformation and enlargement of the trophonts without attachment onto the solid substrate. FCS is usually used to provide additional nutrients and other growth factors favorable to the survival and multiplication of cultured cells in the in vitro techniques (Freshney, 2000).

The transformation of the theronts into trophonts in the liquid media seems advantageous to the in vitro culture since the technique could eliminate reliance on a solid phase as an attachment substrate mimicking a fish host. In all experiments, the transformation of theronts to trophonts and subsequent enlargement took more time than the development in vivo. In fish host epithelium, the rotating $C$. irritans trophonts ingest various host cells including leucocytes, body fluids and tissue debris (Colorni, 1987; Colorni and Diamant, 1993; Dickerson and Dawe, 1995). This suggests that vital nutrients provided by the fish and required for the transformation of trophonts into tomonts are not available in the artificial media.

Under natural conditions, in vivo trophonts are protected from external conditions by the fish host epithelial cells surrounding them. In an in vitro culture, the trophonts are exposed to hazards posed by antibacterial or fungicidal agents present in the media, which could have contributed to the demise of the soft-bodied trophonts. Fragility of their body was observed when the trophonts, especially those that adhered to culture plates, easily disintegrated during pipetting. The presence of a sticky surface which enabled the trophonts to adhere to the plate may be associated with secretory mucocysts as a prelude to a cyst wall formation in tomonts (Colorni and Diamant, 1993). However, we did not observe any transformation of the in vitro raised trophonts into cystic tomonts.

The macronucleus observed in the small in vitro raised trophonts is consistent with that of Colorni and Diamant (1993) who described a macronucleus in the in vivo young trophonts consisting of four linked bead-like segments twisted in a crescent-shaped alignment. As the in vivo trophont matures, the macronucleus becomes larger and elongated. This might indicate that the in vitro raised trophonts with an elongated or larger macronucleus had a more advanced stage of maturity than trophonts with the four-lobed macronucleus. This also indicates that some in vitro raised trophonts could have undergone a level of maturation without significantly increasing in size. No distinct macronucleus in any DAPI-stained large trophonts has been observed. The electron-dense material that filled the alveoli of more mature trophonts (Matthews et al., 1993) might have blocked the staining of the macronucleus.

In summary, the transformation of the $C$. irritans theronts into trophonts and the succeeding enlargement of trophonts either in the solid or liquid substrate have been achieved in vitro and are reported for the first time in the present study. Best growth was attained in the 
liquid medium supplemented with $20 \%$ FCS that resulted to trophont sizes comparable to the in vivo trophonts. Growth of trophonts in liquid medium appears advantageous because this facilitates collection of the parasite for further studies. No trophont, however, was observed to have transformed into a tomont. Some significant features such as cilia, cytostome and macronucleus of the in vitro raised trophonts were shown comparable to the in vivo raised trophonts. This indicates that the in vitro culture of $C$. irritans is possible. The ciliary structures of in vitro raised trophonts may provide antigens for immune studies. The study also provides clues on different culture media that may be screened and modified for a successful propagation of $C$. irritans and completion of its life cycle in vitro.

\section{Acknowledgements}

We thank Dr. Angelo Colorni, Department of Pathobiology, Israel Oceanographic and Limnological Research, Israel for sharing his expertise; Dr. Kazuo Ogawa, Department of Aquatic Bioscience, The University of Tokyo, Japan and the other two reviewers for giving helpful comments; Dr. In-Cho Lee, Institute of Fishery Science, National Taiwan University for the statistical analysis of the data; Dr. Chien-Yuan Pan for the Leica DM IRE2 microscopy; Ms. Yu-Fen Huang for the Leica TCS SP2 microscopy; Dr. Shau-Chi Chi for the JF1 epithelial cells; Dr. Hsi-Yuan Yang for the DAPI staining materials; and Ms. Fan-Hao Hsu for assisting in the DAPI staining of parasite samples. We also thank the Council of Agriculture (92AS-92.2-FA-F1), Taiwan for the financial support.

\section{References}

Bryant, M. S., R. P. Lee, R. J. G. Lester and R. J. Whittington (1999): Anti-immunoglobulin antisera used in an ELISA to detect antibodies in barramundi Lates calcarifer to Cryptocaryon irritans. Dis. Aquat. Org., 36, 21-28.

Burgess, P. J. and R. A. Matthews (1995): Cryptocaryon irritans (Ciliophora): acquired protective immunity in the thicklipped mullet, Chelon labrosus. Fish Shellfish Immunol., 5, 459-468.

Burkart, M. A., T. G. Clark and H. W. Dickerson (1990): Immunization of channel catfish, Ictalurus punctatus Rafinisque, against Ichthyophthirius multifiliis (Fouquet): Killed versus live vaccines. J. Fish Dis., 13, 445-454.

Chi, S. C., W. W. Hu and B. J. Lo (1999) Establishment and characterization of a continuous cell line (GF-1) derived from grouper, Epinephelus coioides (Hamilton): a cell line susceptible to grouper nervous necrosis virus (GNNV). J. Fish Dis., 22, 173-182.

Clark, T. G., H. W. Dickerson and T. L. Lin (1987): In vitro response of Ichthyophthirius multifilis to sera from immune channel catfish. J. Fish Biol., 31, 203-208.

Clark, T. G., H. W. Dickerson and R. C. Findly (1988): Immune response of channel catfish to ciliary antigens of Ichthyophthirius multifiliis. Dev. Comp. Immunol., 12, 581-594.

Colorni, A. (1987): Biology of Cryptocaryon irritans and strategies for its control. Aquaculture, 67, 236-237.

Colorni, A. and P. J. Burgess (1997): Cryptocaryon irritans Brown 1951, the cause of white spot disease in marine fish: an update. Aquarium Sci. Conserv., 1, 217-238.

Colorni, A. and A. Diamant (1993): Ultrastructural features of Cryptocaryon irritans, a ciliate parasite of marine fish. Europ. J. Protistol., 29, 425-434.

Dickerson, H. W. and T. G. Clark (1996): Immune response of fishes to ciliates. Ann. Rev. Fish Dis., 6, 107-120.

Dickerson, H. W. and D. L. Dawe (1995): Ichthyophthirius multifiliis and Cryptocaryon irritans (Phylum Ciliophora). In "Fish diseases and disorders, Vol. 1, Protozoan and metazoan infections" (ed. by P. T. K. Woo). Cambridge, CAB International. pp. 181-227.

Ekless, L. M. and R. A. Matthews (1993): Ichthyophthirius multifiliis: axenic isolation and short-term maintenance in selected monophasic media. J. Fish Dis., 16, 437-447.

Freshney, R. I. (2000): Culture of animal cells: a manual of basic technique, 4th edn. Wiley-Liss, New York. 577 p.

Jee, B. Y., K. H. Kim, S. I. Park and Y. C. Kim (2000): A new strain of Cryptocaryon irritans from the cultured olive flounder Paralichthys olivaceus. Dis. Aquat. Org., 43, 211-215

Matthews, B. F., R.A. Matthews and P. J. Burgess (1993): Cryptocaryon irritans Brown, 1951 (Ichthyophthiriidae): the ultrastructure of the somatic cortex throughout the life cycle. J. Fish Dis., 16, 339-349.

Nielsen, C. V. and K. Buchmann (2000): Prolonged cultivation of Ichthyophthirius multifiliis using an EPC cell line as substrate. Dis. Aquat. Org., 42, 215-219.

Noe, J. G. and H. W. Dickerson (1995): Sustained growth of Ichthyophthirius multifiliis at low temperature in the laboratory. J. Parasitol., 81, 1022-1024.

Noga, E. J. (1987): Propagation in cell culture of the dinoflagellate Amyloodinium, an ectoparasite of marine fishes. Science, 236, 1302-1304.

Noga, E. J. and C. E. Bower (1987): Propagation of the marine dinoflagellate Amyloodinium ocellatum under germ-free conditions. J. Parasitol., 73, 924-928.

Uzmann, J. R. and S. H. Hayduk (1963): In vitro culture of the flagellate protozoan Hexamita salmonis. Science, $\mathbf{1 4 0}$ 290-291.

Wang, R. and M. Belosevic (1994): Cultivation of Trypanosoma danilewskyi (Laveran \& Mesnil, 1904) in serum-free medium and assessment of the course or infection in goldfish, Carassius auratus (L.). J. Fish Dis., 17, 47-56.

Woo, P. T. K. and S. Li (1990): In vitro attenuation of Cryptobia salmositica and its use as a live vaccine against cryptobiosis in Onchorhyncus mykiss. J. Parasitol., 76, 752-755.

Yambot, A. V., Y. L. Song and H. H. Sung (2003): Characterization of Cryptocaryon irritans, a parasite isolated from marine fishes in Taiwan. Dis. Aquat. Org., 54, 147-156.

Yano, T. (1992): Assays of hemolytic complement activity. In "Techniques in fish immunology" (ed. by J.S. Stolen, T.C. Fletcher, D. P. Anderson, S. L. Kaattari, A. F. Rowley). SOS Publications, Fair Haven, NJ, pp. 131-141.

Yoshinaga, T. and J. Nakazoe (1997): Acquired protection and production of immobilization antibody against Cryptocaryon irritans (Ciliophora, Hymenostomatida) in mummichog (Fundulus heteroclitus). Fish Pathol., 32, 229-230. 